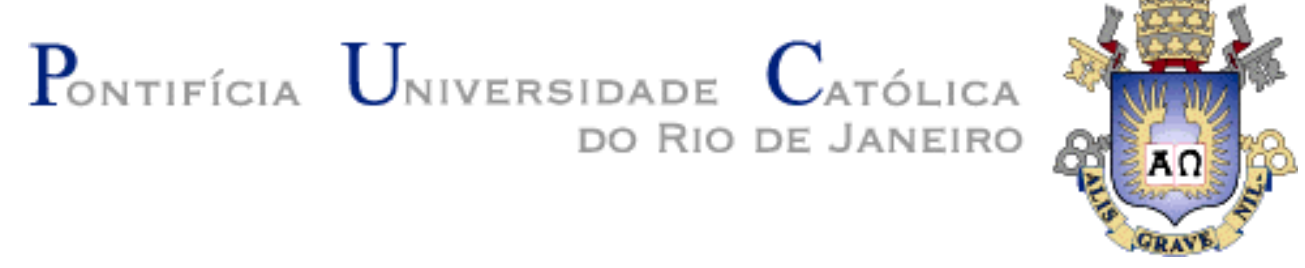

Isela Macía Bertrán

\title{
On the Detection of Architecturally-Relevant Code Anomalies in Software Systems
}

\author{
Tese de Doutorado
}

Thesis presented to the Programa de Pós-Graduação em Informática of the Departamento de Informática, PUC-Rio as partial fulfillment of the requirements for the degree of Doutor em Informática.

Advisor: Prof. Arndt von Staa Co-advisor: Prof. Alessandro Fabricio Garcia 
Isela Macía Bertrán

On the Detection of Architecturally-Relevant Code Anomalies in Software Systems

Thesis presented to the Programa de Pós-Graduação em Informática of the Departamento de Informática, PUC-Rio as partial fulfillment of the requirements for the degree of Doutor em Informática.

Prof. Arndt von Staa

Advisor

Departamento de Informática - PUC-Rio

Prof. Alessandro Fabricio Garcia Co-advisor Departamento de Informática - PUC-Rio

Profa. Yuanfang Cai Drexel University

Prof. Paulo Henrique Monteiro Borba Universidade Federal de Pernambuco (UFPE)

Prof. Carlos José Pereira de Lucena Departamento de Informática - PUC-Rio

Prof. Renato Fontoura de Gusmão Cerqueira Departamento de Informática - PUC-Rio

Prof. José Eugenio Leal Coordinator of the Centro Técnico Científico da PUC-Rio 
All rights reserved. It is not allowed the total or partial reproduction of this work without the university, author and supervisor authorization.

\section{Isela Macía Bertrán}

She completed her undergraduate studies in Computer Science at the University of Havana, Cuba in 2006. She received her Master degree in Informatics from the Pontifical Catholic University of Rio de Janeiro (PUC-Rio) in 2009.

Bibliographic data

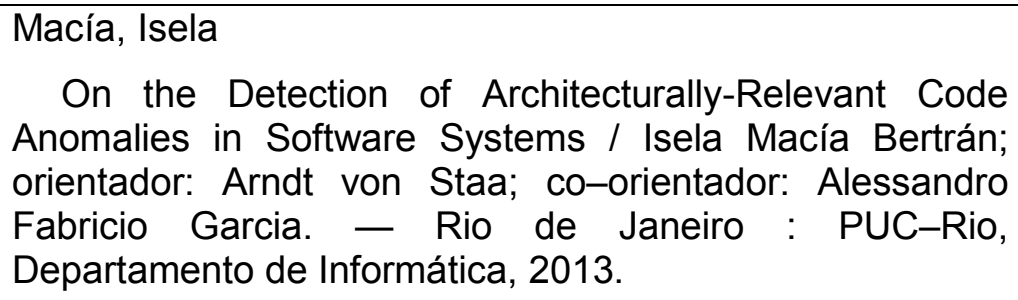

On the Detection of Architecturally-Relevant Code Anomalies in Software Systems / Isela Macía Bertrán; orientador: Arndt von Staa; co-orientador: Alessandro Fabricio Garcia. - Rio de Janeiro : PUC-Rio, Departamento de Informática, 2013.

260 f: il.(color.) ; $30 \mathrm{~cm}$

1. Tese (Doutorado em Informática) - Pontifícia Universidade Católica do Rio de Janeiro, Rio de Janeiro, 2013.

Inclui Bibliografia.

1. Informática - Tese. 2. Arquitetura de Software. 3. Degradação Arquitetural. 4. Anomalia de Código. 5. Anomalia de Código Arquiteturalmente Relevante. I. Staa, Arndt. II. Garcia, Alessandro. III. Pontifícia Universidade Católica do Rio de Janeiro. Departamento de Informática. IV. Título. 


\section{Acknowledgements}

First of all, I would like to thank my supervisors, Arndt von Staa and Alessandro Garcia. In particular, I want to express my deepest appreciation to Arndt for his amazing wisdom and for giving me freedom to shape my research. Arndt, thanks a lot for always keeping me on the right track and making me think. I must also thank Alessandro Garcia for teaching me how to do research, guiding me in all the process with his extensive knowledge, enthusiasm and motivation.

Special thanks to Nenad Medvidovic for his honest criticism, insightful discussions, questions and for helping me during my stay in Los Angeles.

I am also thankful to the members of my examining committee, who generously contributed with their time and expertise: Carlos Lucena, Renato Cerqueira, Yuanfang Cai and Paulo Borba.

Very special thanks to Julio for the unique way in which he loves, understands, and supports me day by day, to my parents and to my family who have believed in me and encouraged me since the first day .

Special thanks to Chico and Camila for the long talks and for supporting me in the bureaucratic tasks, and to Roberta for the hard work together and for reviewing the English in this thesis.

I thank Rosi for supporting me and helping me.

Thanks to my colleagues from the Laboratory of Software Engineering (LES) at PUC-Rio for the wonderful environment, to my colleagues from the Opus Research Group at PUC-Rio for the technical discussions and to my colleagues and staff members from the Department of Computer Science at USC for making my stay there an extraordinary experience.

Thanks to Vera for her constant smile and for lending me her phone booth.

Many thanks to the faculty and staff members from the Informatics Department at PUC-Rio, who helped me during the last six years.

My doctoral studies were financially supported by CNPq and CAPES. These institutions have all my gratitude. 


\section{Abstract}

Macía, Isela; Staa, Arndt; Garcia, Alessandro. On the Detection of Architecturally-Relevant Code Anomalies in Software Systems. Rio de Janeiro, 2013. 260p. DSc. Thesis - Departamento de Informática, Pontifícia Universidade Católica do Rio de Janeiro.

Code anomalies can signal software architecture degradation. However, the identification of architecturally-relevant code anomalies (i.e. code anomalies that strongly imply architectural deficiencies) is particularly challenging due to: (i) lack of understanding about the relationship between code anomalies and architectural degradation, (ii) the focus on source code anomaly detection without considering how it relates to the software architecture, and (iii) lack of knowledge about how reliable these detection techniques are when revealing architecturallyrelevant code anomalies. This thesis presents techniques for identifying architecturally-relevant code anomalies. Architecture-sensitive metrics and detection strategies were defined to overcome the limitations of conventional detection strategies. These metrics and strategies leverage traces that can be established between architectural views and system implementation. The thesis also documents code anomaly patterns (i.e. recurring anomaly relationships) that are strongly related to architectural problems. A tool, called SCOOP, was developed to collect the architecture-sensitive metrics, apply the new detection strategies, and identify the documented code anomaly patterns. Using this tool, we evaluated our technique in a series of empirical studies, comparing its accuracy with that of conventional detection techniques when identifying architecturallyrelevant code anomalies.

\section{Keywords}

Software Architecture; Architectural Degradation; Code Anomaly; Architecturally-Relevant Code Anomaly. 


\section{Resumo}

Macía, Isela; Staa, Arndt; Garcia, Alessandro. Detecção de Anomalias de Código Arquiteturalmente Relevantes em Sistemas de Software. Rio de Janeiro, 2013. 260p. Tese de Doutorado - Departamento de Informática, Pontifícia Universidade Católica do Rio de Janeiro.

Anomalias de código podem sinalizar a degradação da arquitetura de software. No entanto, a identificação de anomalias de código arquiteturalmente relevantes (ou seja, aquelas que implicam em deficiências arquiteturais) é particularmente difícil devido: (i) a falta de compreensão sobre a relação existente entre anomalias de código e degradação arquitetural, (ii) ao fato do processo de detecção de anomalias ter como foco somente o código fonte, sem considerar como ele se relaciona com sua arquitetura, e (iii) a falta de conhecimento sobre a confiabilidade das técnicas de detecção em revelar anomalias de código que são arquiteturalmente relevantes. Esta tese apresenta técnicas para identificar anomalias de código que são arquiteturalmente relevantes. Métricas sensíveis à arquitetura e estratégias de detecção foram definidas para superar as limitações das técnicas de detecção convencionais. Estas métricas e estratégias aproveitam rastros que podem ser estabelecidos entre as visões arquiteturais e a implementação dos sistemas. A tese também documenta padrões de anomalias de código (ou seja, relações recorrentes de anomalias) que estão relacionados com problemas arquiteturais. Uma ferramenta, chamada de SCOOP, foi desenvolvida para coletar as métricas sensíveis à arquitetura, aplicar as novas estratégias de detecção, e identificar os padrões de anomalias de código. Usando esta ferramenta, a técnica proposta foi avaliada em uma série de estudos empíricos, comparando sua acurácia com técnicas convencionais de detecção durante o processo de identificação de anomalias de código que são arquiteturalmente relevantes.

\section{Palavras-chave}

Arquitetura de Software; Degradação Arquitetural; Anomalia de Código; Anomalia de Código Arquiteturalmente Relevante. 


\section{Summary}

1 Introduction 17

1.1. Motivation 18

1.1.1. Motivating Example 19

1.2. Problem Statement 22

1.3. The State of Art on Code Anomalies and their Empirical Evaluation $\quad 24$

1.4. Research Questions 26

1.5. Outline of the Thesis Structure $\quad 29$

2 Background and Related Work 32

2.1. Software Architecture $\quad 32$

2.2. Architectural Degradation 34

2.2.1. Causes of Architectural Degradation 35

2.2.2. Prevention of Architectural Violations 36

2.2.3. Architectural Anomalies 38

2.2.4. Analysis of Existing Techniques to Prevent Architectural Degradation $\quad 40$

2.2.4.1. Lack of Prescribed Design Decisions 40

2.2.4.2. Lack of Mechanisms to Detect Architectural Anomalies 40

2.3. Code Anomalies 41

2.3.1. Detection of Code Anomalies 42

2.3.2. Removal of Code Anomalies by means of Refactorings 45

2.3.3. Empirical Studies about Code Anomaly Side Effects 46

2.3.4. Analysis of Existing Research on Code Anomalies 47

2.3.4.1. Lack of Extensive Catalogs of Aspect-Oriented Code $\begin{array}{ll}\text { Anomalies } & 48\end{array}$

2.3.4.2. Lack of Knowledge about the Code Anomaly Influence on Architectural Design 
3 Code Anomalies in Aspect-Oriented Programming 52

3.1. Aspect-Oriented Programming 53

3.2. Identification of Code Anomalies $\quad 55$

3.2.1. A Catalog of Already Documented Code Anomalies 55

3.2.2. A Catalog of New Code Anomalies 57

3.2.2.1. Anomalous Pointcut Definition 57

3.2.2.2. Undesirable Interdependencies 61

3.3. Experimental Evaluation 66

3.3.1. Target Systems $\quad 67$

3.3.2. Study Phases and Assessment Procedures 68

3.3.3. Findings on Code Anomaly Occurrences 69

3.3.4. Threats to Validity $\quad 74$

$\begin{array}{ll}\text { 3.4. Summary } & 76\end{array}$

4 Impact of Code Anomalies on Architectural Degradation 78

4.1. Study Definition and Design 79

4.1.1. Hypotheses 81

4.1.2. Variable Selection 81

4.1.3. Selection Criteria and Target Systems 82

4.1.4. Procedures for Data Collection 83

4.2. Findings on the Impact of Code Anomalies 90

4.2.1. Are Anomalous Code Elements Architecturally-Relevant? 90

4.2.2. Are Particular Characteristics of Code Anomalies Indicators of Architectural Degradation Symptoms? 93

4.2.2.1. Type of Code Anomalies 94

4.2.2.2. Earliness of Code Anomalies 96

4.2.3. Are Architecturally-Relevant Code Anomalies often

Refactored? 100

4.3. Threats to Validity 103

4.4. Summary 104 
5 Analysis of Conventional Detection Strategies 107

5.1. Study Definition and Design 108

5.1.1. Hypotheses 109

5.1.2. Variable Selection 110

5.1.3. Selection Criteria and Target Systems 110

5.1.4. Procedures for Data Collection and Analysis 111

5.2. Study Results 113

5.2.1. Accuracy of Detecting Architectural Violations $\quad 115$

5.2.2. Accuracy of Detecting Architectural Anomalies 116

5.2.3. Hypotheses and Overall Accuracy Results 116

5.2.4. Analysis of Overlooked Code Anomalies 117

5.2.4.1. Inability to Analyze Properties of Architectural Concerns in the Source Code 118

5.2.4.2. Inability to Identify Architectural Information in the $\begin{array}{ll}\text { Source Code } & 119\end{array}$

5.2.4.3. Patterns of Code Anomalies 120

5.2.4.4. Architectural Design and Strategy Accuracy 122

5.3. Threats to Validity 123

5.4. Summary 125

6 Detection of Architecturally-Relevant Code Anomalies with $\begin{array}{ll}\text { Architectural-Sensitive Information } & 127\end{array}$

6.1. Basic Formalism 129

6.1.1. System Meta-Model 129

6.1.2. Meta-Model Instantiation 133

6.2. Architecture-Sensitive Metrics 134

6.2.1. Metrics for Architectural Components 135

6.2.2. Metrics for Architectural Concerns 138

6.3. Architecture-Sensitive Detection Strategies 140

6.3.1. Detection Strategies for Element Anomalies 141

6.3.1.1. Feature Envy (FE) 141

6.3.1.2. Misplaced Class (MC) 142

6.3.1.3. Long Method (LC) 143 
$\begin{array}{ll}\text { 6.3.1.4. God Class (GC) } & 144\end{array}$

6.3.2. Detection Strategies for Collaborative Anomalies 145

6.3.2.1. Shotgun Surgery (SS) 145

6.3.2.2. Intensive Coupling (IC) 146

$\begin{array}{ll}\text { 6.3.2.3. Dispersed Coupling } & 147\end{array}$

6.4. Assessment of Architecture-Sensitive Strategies 149

6.4.1. Hypotheses 150

6.4.2. Variable Selection 151

6.4.3. Selection Criteria and Target Systems 152

6.4.4. Procedures for Data Collection and Analysis 153

6.4.5. Findings on Architecture-Sensitive Detection Strategies 156

6.4.5.1. Accurate Detection of Architecturally-Relevant

Code Anomalies 156

6.4.5.2. Impact of Architecture-Sensitive Information is Manifold 159

6.4.5.3. Impact of Concern Granularity Level 164

6.4.6. Imperfections in the Detection of Architecturally-Relevant Anomalies 166

6.4.7. Threats to Validity 168

$\begin{array}{ll}\text { 6.5. Summary } & 169\end{array}$

7 Patterns of Code Anomalies 171

7.1. Defining Code Anomaly Patterns 173

7.2. Intra-Component Patterns 173

7.2.1. Multiple-Anomaly Syndrome 174

7.2.2. Similar Anomalous Neighbors 177

7.3. Inter-Component Patterns 180

7.3.1. External Attractor 180

7.3.2. External Addictor 184

7.3.3. Replicated External Network 187

7.4. Inheritance-based Patterns 190

7.4.1. Hereditary Anomaly 191

7.4.2. Mutant Anomaly 194

$\begin{array}{ll}\text { 7.5. Concern-based Patterns } & 197\end{array}$ 
$\begin{array}{ll}\text { 7.5.1. Concern Overload } & 198\end{array}$

7.5.2. Misplaced Concern 200

7.6. Correlating Code Anomaly Patterns 203

7.7. SCOOP: Detecting Architecturally-Relevant Code Anomalies 205

$\begin{array}{ll}\text { 7.7.1. The SCOOP Inputs } & 206\end{array}$

$\begin{array}{ll}\text { 7.7.2. The SCOOP Engine } & 207\end{array}$

7.7.3. The SCOOP User Interface 208

7.8. Assessment Code Anomaly Patterns 211

$\begin{array}{ll}\text { 7.8.1. Hypotheses } & 212\end{array}$

$\begin{array}{ll}\text { 7.8.2. Variable Selection } & 212\end{array}$

7.8.3. Selection Criteria and Target Systems 213

7.8.4. Procedures for Data Collection 213

$\begin{array}{ll}\text { 7.8.5. Study Results } & 214\end{array}$

7.8.5.1. Frequency of Patterns in the Target Systems 214

7.8.5.2. Code Anomaly Patterns and Architectural Degradation 217

7.8.5.3. Specific Code Anomaly Patterns and Architectural Degradation 223

7.9. Threats to Validity 225

$\begin{array}{ll}\text { 7.10. Summary } & 227\end{array}$

8 Conclusions and Future Work 230

8.1. Revisiting the Thesis Contributions 231

$\begin{array}{ll}\text { 8.2. Future Work } & 235\end{array}$

$\begin{array}{ll}\text { References } & 239\end{array}$

$\begin{array}{ll}\text { Appendix A: System Characteristics } & 253\end{array}$

Appendix B: Detection Strategies and Thresholds 255

$\begin{array}{ll}\text { Appendix C: BNF SCOOP Grammar } & 259\end{array}$

$\begin{array}{ll}\text { Appendix D: SCOOP Rules File } & 260\end{array}$ 


\section{List of Figures}

Figure 1.1: A design slice of the Health Watcher system architecture. 20

Figure 3.1: Example of an aspect in AspectJ. 55

Figure 3.2: Example of God Pointcut.

Figure 3.3: Example of Idle Pointcut. $\quad 60$

Figure 3.4: Example of Redundant Pointcut. 61

Figure 3.5: Example of Forced Join Point. 62

Figure 3.6: Example of God Aspect. $\quad 64$

Figure 3.7: Example of Composition Bloat. 66

Figure 4.1: Impact of an early code anomaly through the system evolution. 98

Figure 4.2: Refactorings and architecturally-relevant code anomalies. 101

Figure 5.1: Accuracy of detection strategies. 113

Figure 5.2: Example of neglected God Class. 119

Figure 6.1: System meta-model. 130

Figure 6.2: A slice of the logistic system design. 131

Figure 6.3: A slice of the logistic system design. 136

Figure 6.4: Precision rates (\%) when components do not match packages. $\quad 160$

Figure 6.5: Recall rates (\%) when components do not match packages. $\quad 161$

Figure 6.6: Accuracy rates (\%) at different granularity levels of concerns. $\quad 165$

Figure 7.1: Abstract representation of Multiple-Anomaly Syndrome. 175

Figure 7.2: Occurrence of Multiple-Anomaly Syndrome in MobileMedia. 177

Figure 7.3: Abstract representation of Similar Anomalous Neighbors. $\quad 178$

Figure 7.4: Occurrence of Similar Anomalous Neighbors in PDP 180

Figure 7.5: Abstract representation of External Attractor. 181

Figure 7.6: Occurrence of External Attractor in HW. 184

Figure 7.7: Abstract representation of External Addictor. 185

Figure 7.8: Abstract representation of Replicated External Network. 187

Figure 7.9: Occurrence of External Addictor in HW 188

Figure 7.10: Occurrence of Replicated External Network in HW. 190

Figure 7.11: Abstract representation of Hereditary Anomaly. 192

Figure 7.12: Occurrence of Hereditary Anomaly in PDP. 194 
Figure 7.13: Abstract representation of Mutant Anomaly.

Figure 7.14: Occurrence of the Mutant Anomaly in MIDAS. 197

Figure 7.15: Abstract representation of Concern Overload. 198

Figure 7.16: Occurrence of Concern Overload pattern in the MIDAS system. 200

Figure 7.17: Abstract representation of Misplaced Concern. 201

Figure 7.18: Occurrence of Misplaced Concern in the MIDAS. 203

Figure 7.19: Relationships between code anomaly patterns. 204

Figure 7.20: Abstract representation of the SCOOP architecture. 205

Figure 7.21: Configuration of code anomaly patterns in SCOOP. 205

Figure 7.22: Code anomalies view. 210

Figure 7.23: Code anomaly patterns view. 210

Figure 7.24: Anomalous code elements taking part in the patterns. 217

Figure 7.25: Precision of patterns vs. detection strategies in the identification of architecturally-relevant code anomalies. 221

Figure 7.26: Recall of patterns vs. detection strategies in the identification of architecturally-relevant code anomalies. 


\section{List of Tables}

Table 1.1: Publications directly related to this thesis. 28

Table 1.2: Indirect publications. $\quad 29$

Table 2.1. Tools for code anomaly detection and source code analysis $\quad 44$

Table 3.1: Criteria used for the selection of target systems 67

Table 3.2: Analyzed concerns in target systems 68

Table 3.3: Code anomaly occurrences in iBATIS. $\quad 70$

Table 3.4: Code anomaly occurrences in Aspectual Watcher. 70

Table 3.5: Code anomaly occurrences in Aspectual Media. 70

Table 3.6: Simultaneous occurrences of code anomalies. 74

Table 4.1: Research questions and hypotheses of the study. 81

Table 4.2: Criteria used for the selection of target systems. 82

Table 4.3: Architectural concerns considered in the study. 85

Table 4.4: Architectural anomalies analyzed in the study. 87

Table 4.5: Code anomalies analyzed in the study. $\quad 88$

Table 4.6: Fisher's test results for architectural violations. 91

Table 4.7: Fisher's test results for architectural anomalies. 91

Table 4.8: Significant p-values for architectural violations. 95

Table 4.9: Significant p-values for architectural anomalies. 95

Table 4.10: Proportions of effective and non-effective refactorings. 102

Table 5.1: Research questions and hypotheses of the study. 109

Table 5.2: Criteria used for the selection of target systems. 110

Table 5.3: Results for the analyzed detection strategies. 114

Table 6.1: Meta-Model instantiation. 134

Table 6.2: Summary of the suite of architecture-sensitive metrics. 134

Table 6.3: Research questions and hypotheses of the study. 150

Table 6.4: Criteria used for the selection of target systems. 152

Table 6.5: Architectural concerns considered in this study for S1, S2

and S3. 153

Table 6.6: Results for the analyzed architecture-sensitive detection strategies. 
Table 6.7: Results for the analyzed conventional detection strategies.

Table 7.1: Research questions and hypotheses of the study. 212

Table 7.2: Code anomaly patterns per target system. 218

Table 7.3: Contingency table and Fisher's test results. 218

Table 7.4: Mann-Whitney's test results and Cohen's $d$ effort. 223

Table 7.5: Spearman's rank correlation results. 223

Table B-1: Thresholds used in the conventional strategies. 256

Table B-2: Thresholds used for the conventional metrics in the architecture-sensitive strategies. 257

Table B-3: Thresholds used for the architecture-sensitive metrics in the architecture-sensitive strategies. 258 